\title{
IMPLEMENTASI AUGMENTED REALITY (AR) BERBASIS ANDROID SEBAGAI PENGENALAN RUMAH ADAT INDONESIA BAGIAN BARAT
}

\author{
Novia Sulistyowati ${ }^{1)}$, Febrian Murti Dewanto ${ }^{2)}$, Rahmat Robi Waliyansyah ${ }^{3)}$ \\ ${ }^{1,2,3}$ Fakultas Teknik dan Informatika, Universitas PGRI Semarang \\ lee25donghae@gmail.com ${ }^{1)}$, febrianmd@ upgris.ac.id ${ }^{2)}$, rahmat.robi.waliyansyah@ @pgris.ac.id ${ }^{3)}$
}

\begin{abstract}
A traditional house is a house that has a unique building characteristic in an area that describes the culture of the area itself. Traditional houses are also unique in terms of form, function and meaning of the building. As Indonesians, we must introduce one of the existing cultures so that it is not forgotten by the community, especially school children. Judging from the development of technology, we must make new things in introducing traditional houses. From the results of research conducted at SD IT BINA INSANI, the teachers there still use conventional media in the form of textbooks and thematic books for the learning process. Therefore, the authors created an application to introduce western Indonesian traditional houses using Augmented Reality called RA$I B B$ as an introduction medium. This application is based on Android so that teachers can easily explain material about traditional houses and can show traditional houses in $3 D$ without having to come directly to the province. And for students to be able to study traditional houses wherever and whenever. The making of this application uses the waterfall method for the development stage. The RA-IBB application contains materials about western Indonesian traditional houses and their $3 d$ objects and quiz questions that use random shuffle algorithm questions. The random shuffle algorithm is a randomized question from an array or record. Based on the User Acceptance Test (UAT) for teachers, the results obtained from several aspects, namely the design aspect yields a percentage of $91 \%$, the application information aspect produces a percentage of 91.
\end{abstract}

Keywords: Rumah Adat, Augmented Reality, Algoritma Shuffle Random

\section{PENDAHULUAN}

Bangsa Indonesia adalah bangsa besar dengan keragaman background bahasa, budaya, agama dan etnis. Indonesia merupakan negara yang keberagaman dan keunikannnya sangat kaya di dalamnya. Dengan keanekaragaman yang sangat banyak maka terbentuklah bermacam-macam kebudayaan pada tiap daerah yang diikuti dengan ciri khas dan keunikannya (Sutiari et al., 2018). Salah satu keanekaragaman budaya yang dimiliki adalah rumah adat. Indonesia dibagi menjadi 3 bagian wilayah yaitu barat, timur dan tengah. Rumah adat yaitu rumah yang mempunyai keunikan bangunan tertentu di Indonesia yang menggambarkan kebudayaan pada daerah tersebut (Sutiari et al., 2018). Disetiap rumah adat mempunyai keunikan tersendiri sesuai dengan kearifan lokal daerahnya. Memperkenalkan rumah adat yang ada di Indonesia menjadi hal penting bagi masyarakat khususnya anak sekolah, dengan adanya materi pembelajaran yang ada di buku paket tematik membuat siswa belajar akan keragaman rumah adat.
Beberapa penelitian terkait Augmented Reality : Pengenalan buah-buahan dengan menggunakan Augmented Reality sebagai media pembelajaran. Berdasarkan uji coba, aplikasi yang dikembangkan cukup efektif dengan penilaian $86 \%$ dari 30 responden (Pramono \& Setiawan, 2019). Pengenalan rumah adat Kalimantan Barat dengan menggunakan Mobile Augmented Reality. Pengujian dilakukan dengan perhitungan kuisioner. Metode yang digunakan adalah Likert's Summated Ratting (LSR) dan didapatkan score 1771. Nilai tersebut dikategorikan positif yang berarti aplikasinya bisa diimplementasikan dengan baik (Rahadi et al., 2017). Promosi tempat wisata yang unggul di Provinsi Riau dengan menggunakan Mobile Augmented Reality berbasis 3D Object Tracking. Beberapa pengujian dilakukan untuk memperoleh pengaruh dari jarak antara spidol dengan kamera handphone, agar mendapatkan pengukuran jarak yang ideal untuk mencitrakan objek 3D yaitu $40 \mathrm{~cm}$. Uji coba software ini bisa mendeteksi marker dengan jarak paling dekat adalah $10 \mathrm{~cm}$ dan terjauh yaitu $67 \mathrm{~cm}$, serta 
mendapatkan mean antara 0,80 sampai 0,93 detik (Rio et al., 2016). Pengenalan rangka manusia berbasis Mobile Augmented Reality. Penelitian ini memiliki tujuan untuk menciptakan pembelajaran yang interaktif, serta membantu mahasiswa kedokteran dalam menghafal \& memahami bentuk anatomi tubuh secara 3D menjadi lebih praktis dengan menggunakan teknologi Mobile Augmented Reality (Wisnugroho et al., 2015). Pemanfaatan augmented reality untuk pembelajaran 3D Printing di Sekolah Tinggi. Disini AR sangat membantu untuk murid yang kurang memiliki skill/pengetahuan. Sehigga murid-murid tersebut dalam mengikuti pembelajaran dengan lebih baik (Scaravetti \& Doroszewski, 2019). AR juga digunakan oleh sebagian pengajar sebagai alat untuk membantu mereka dalam pembelajaran. Sehingga dari metode ini akan dievaluasi untuk bisa dibuatkan kebijakan oleh pemerintah sebagai standar pembelajaran di Sekolah (Klimova et al., 2018).

Dari beberapa penelitian tersebut, maka penulis ingin memanfaatkan teknologi Augmented Reality yang berbasis Andorid untuk lebih memperkenalkan rumah adat kepada siswa-siswi di SD IT BINA INSANI. SD IT BINA INSANI adalah sekolah islam terpadu yang berada di Kota Semarang dan sudah berdiri semenjak tahun 2005. Sekolah ini masih menggunakan media konvensional untuk proses belajar, agar memudahkan guru dalam mengajar perlu adanya bantuan teknologi salah satunya yaitu augmented reality. Augmented Reality (AR) merupakan teknologi yang bisa memadukan benda maya tiga (3D) dan dua dimensi (2D) ke dalam daerah nyata 3D selanjutnya membentuk objek-objek virtual tersebut ke dalam real time. Software telah menggunakan teknologi AR sudah cukup banyak diantaranya adalah untuk edukasi, media pembelajaran dan bisnis (Nugraha et al., 2016).

Dari latar belakang tersebut, maka bisa dijadikan media pembelajaran yang baru dalam menyampaikan informasi terutama pengenalan Rumah Adat Indonesia bagian barat di SD IT BINA INSANI.

\section{METODE PENELITIAN}

Metode yang dipakai pada riset ini yaitu waterfall. Metode Waterfall adalah pengembangan software yang sekuensial/berurutan, di mana arah runut maju dianggap sebagai arus mengalir ke bawah layaknya air terjun serta tahapan-tahapan ang dilalui adalah : perencanaan, pemodelan, implementasi (konstruksi), \& pengujian. Dalam perkembangannnya metode tersebut mempunyai langkah-langkah yang runtut : analisis kebutuhan pengguna, desain sistem, penulisan kode \& pengujian, penerapan \& pemeliharaan program (Gustami, 2016).

\section{a. Analisis kebutuhan}

Pada tahapan ini yaitu analisis terhadap kebutuhan-kebutuhan sistem. Mengumpulkan data yang terkait penelitian, wawancara/survey serta pencarian studi literatur. Seorang sistem analisis harus mencari informasi yang banyak dari pengguna sehingga bisa terbentuk sebuah sistem komputer yang dapat melaksanakan perintah yang diberikan oleh pengguna. Langkah tersebut bisa menghasilkan dokumen kebutuhan pengguna atau bisa juga dikatakan sebagai data yang memiliki hubungan terhadap perancangan pengguna dalam membuat sistem.

\section{b. Desain Sistem}

Tahapan desain yaitu menterjemahkan apa saja kebutuhan dalam pembuatan software yang bisa dipetakan sebelum dimasukkan koding programnya. Tahapan ini hanya fokus pada : arsitektur perangkat lunak, representasi interface, detail dari prosedur algoritma, dan struktur data. Langkah ini bisa menjadi dokumen yang disebut kebutuhan perangkat lunak. Dokumen inilah yang kemudian bisa dipergunakan oleh programmer dalam melaksanakan proses pembuatan sistem.

\section{c. Penulisan Kode Program \& Pengujian}

Penulisan kode program adalah menterjemahkan desain ke dalam bahasa yang bisa dipahami oleh komputer. Penulisan kode 
program dilaksanakan oleh programmer yang mau menterjemahkan proses bisnis yang diinginkan oleh pengguna. Langkah ini adalah langkah real pada pembuatan suatu sistem. Dengan kata lain pemakaian komputer akan dioptimalkan pada langkah tersebut. Apabila penulisan kode program telah selesai, maka akan dilaksanakan pengujian pada sistem yang sudah dibuat. Pengujian ini mempunyai tujuan yaitu mendapatkan kesalahan/bug yang berada pada sistem tersebut dan selanjutnya akan langsung diperbaiki.

\section{d. Penerapan/Pemeliharaan Program}

Tahapan ini merupakan langkah terakhir/final dalam membuat sebuah sistem. Jika sudah melaksanakan analisis, desain dan pengkodean program, maka software tersebut bisa dapat dipergunakan oleh pengguna.

\section{HASIL DAN PEMBAHASAN}

Berdasarkan analisis kebutuhan yang sudah dilaksanakan, dibutuhkan sebuah desain sebelum pembuatan sistem. Pada tahap ini ada 2 desain yaitu desain user interface (UI) dan experience (UX). UX memakai unified modelling language (UML) yang tersusun dari use case, sequence, activity dan class diagram. Desain UI berhubungan dengan tampilan aplikasi. Desain berorientasi objek yaitu metodologi yang mengkombinasikan karakteristik data pada bentuk atribut, karakteristik proses pada bentuk metode \& mengubah sistem menjadi objek (Sylfania, 2016).

\section{a. Use case diagram}

Use case diagram adalah ilustrasi dari skenario interaksi antara sistem dengan pengguna. Use case diagram mengilustrasikan korelasi antara kegiatan yang bisa dilakukan pada sistem dan aktor (Riskal, 2017).

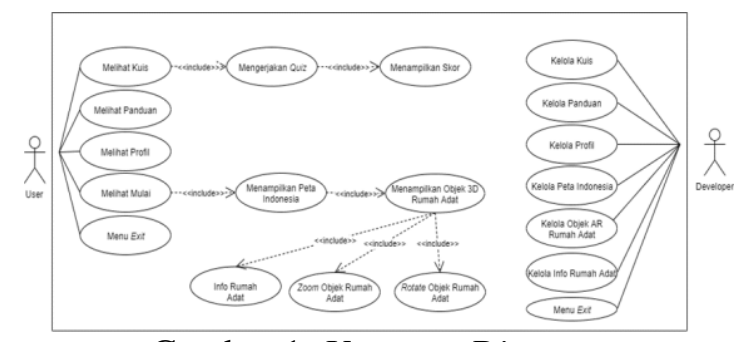

Gambar 1. Use case Diagram
Pada gambar 1 menjelaskan interaksi antara aktor dengan sistem yang dibuat. Dalam use case diagram ini memiliki satu aktor yaitu user. User bisa mengakses menu kuis yang berisi kumpulan kuis tentang rumah adat Indonesia bagian barat, menu Mulai yang berisi peta Indonesia, menu Panduan yang berisi tentang cara penggunaan aplikasi, menu Profil yang berisi tentang informasi dari pengembang dan menu Exit untuk keluar dari software.

\section{b. Activity diagram}

Activity diagram ini mendeskripsikan tahapan alur kerja sistem. Dimulai dari mengklik Menu Mulai yang kemudian user akan melihat peta Indonesia, selanjutnya pilih salah satu Provinsi dan akan diarahkan ke kamera dan marker untuk melihat objek 3D rumah adat yang berisikan informasi, rotate, zoom object. Dalam activity diagram melihat menu mulai dibagi menjadi 3 Activity diagram yaitu Activity diagram info, rotate, dan zoom yang bisa dilihat pada Gambar 2 .

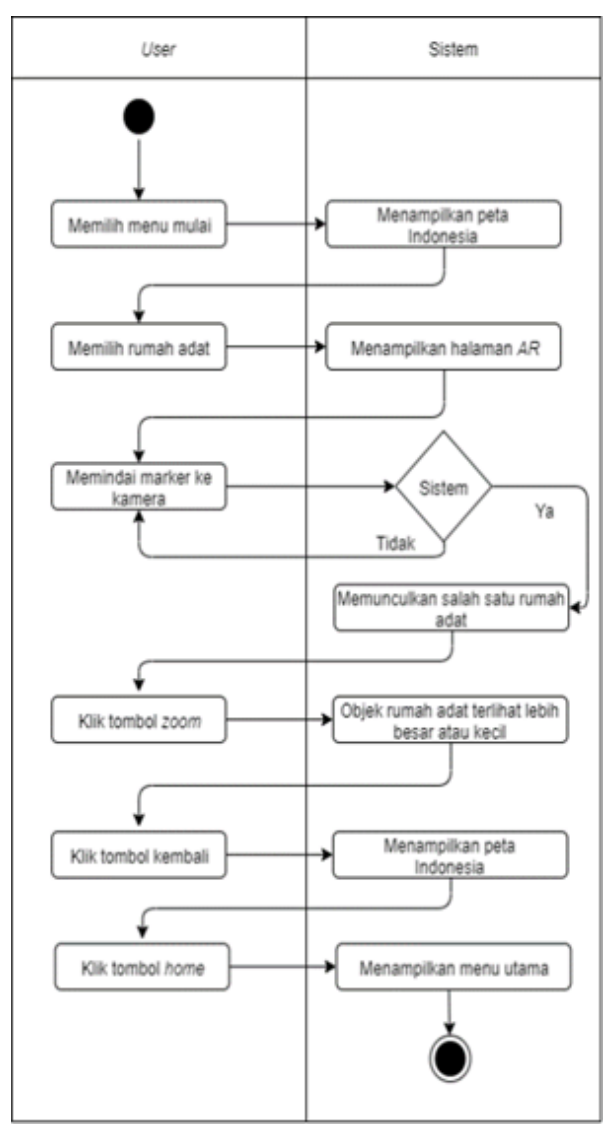

Gambar 2. Activity Diagram 


\section{c. Sequence Diagram}

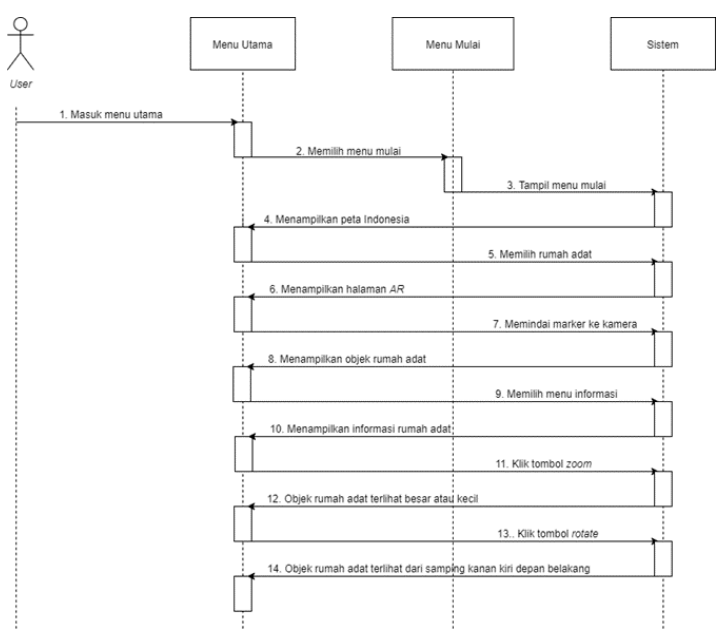

Gambar 3. Sequence Diagram

Sequence diagram ini menggambarkan bagaimana fungsi menu mulai aplikasi. Saat user mengklik menu mulai, user akan melihat halaman yang berisi gambar peta Indonesia selanjutnya user dapat memilih Provinsi yang akan dituju khusus bagian barat. Setelah memilih Provinsi akan diarahkan ke kamera dan marker yang kemudian akan memunculkan objek 3D rumah adat tersebut.

\section{d. Implementasi}

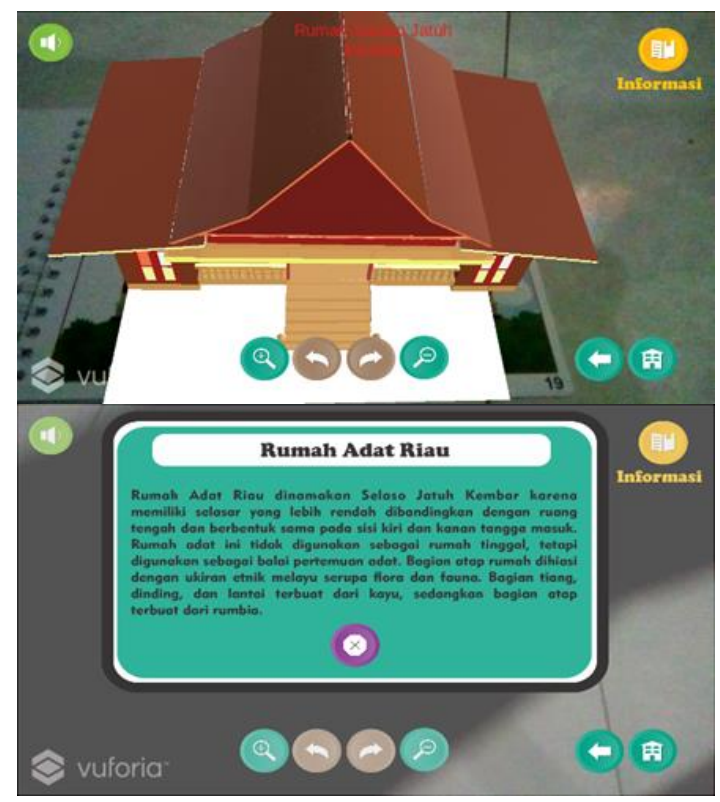

Gambar 4. User Interface Augmented Reality

Pada Gambar 4 menampilkan user interface augmented reality yang memiliki beberapa tombol yaitu tombol zoom in, zoom out, rotasi kanan, rotasi kiri, sound, informasi dan tombol kembali. Gambar tersebut menjelaskan bagaimana objek rumah adat 3D muncul setelah kamera memindai marker.

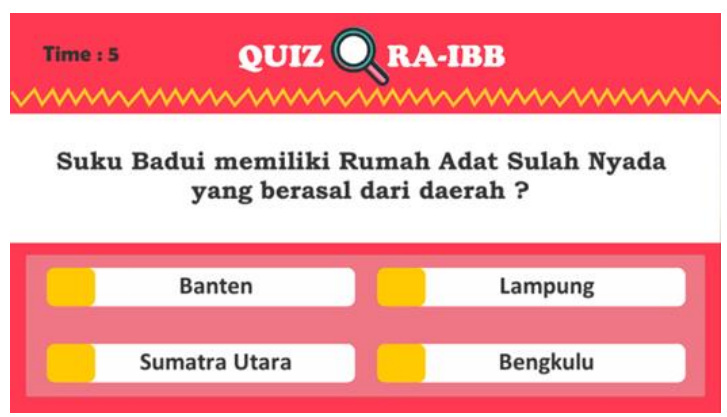

Gambar 5. User Interface Kuis

Pada Gambar 5 user interface kuis menampilkan soal kuis yang digunakan untuk evaluasi setelah mempelajari rumah adat Indonesia bagian barat. Kuis akan teracak apabila user akan mengulangi kuis lagi, dalam hal ini menggunakan sebuah algoritma yaitu Algoritma Shuffle Random. Shuffle Random yaitu urutan indeks yang diacak dari sebuah array/record. Proses acak ini diilustrasikan dengan mencocokkannya pada dek kartu, seluruh kartu dikocok sehingga urutannya menjadi acak. Pada bahasa pemrograman fungsi shuffle random tidak hanya mampu membuat angka yang acak, namun mampu mengacak campuran string dan angka ataupun array string (Yusnita \& Rija'i, 2019).

\section{e. User Acceptance Test}

Hasil user acceptance test didapatkan dari responden yaitu guru kelas 4 dan 5 di SD IT Bina Insani yang bersedia untuk mengisi kuisioner yang penulis berikan. Pengujian user acceptance test dibagi menjadi 3 aspek yaitu aspek desain, aspek informasi aplikasi, dan aspek materi.

Hasil Kuisioner dari Aspek Desain :

1. Tampilan aplikasi RA-IBB menarik.

2. Font tulisan pada aplikasi RA-IBB dapat terbaca dengan baik.

3. Tata letak menu pada aplikasi RAIBB telah sesuai.

4. Penggunaan warna pada aplikasi RAIBB sudah terlihat nyaman oleh user.

5. Kualitas gambar sudah bagus. 
Tabel 1. Hasil Kuisioner Pengujian dari Aspek Desain

\begin{tabular}{|c|c|c|c|c|c|}
\hline \multirow{2}{*}{ Responden } & \multicolumn{5}{|c|}{ Pertanyaan dan Hasil } \\
\cline { 2 - 6 } & 1 & 2 & 3 & 4 & 5 \\
\hline 1 & 5 & 5 & 5 & 5 & 4 \\
\hline 2 & 5 & 4 & 4 & 5 & 4 \\
\hline 3 & 5 & 4 & 4 & 4 & 4 \\
\hline 4 & 5 & 4 & 5 & 5 & 5 \\
\hline Jumlah & 20 & 17 & 18 & 19 & 17 \\
\hline Persentase & $100 \%$ & $85 \%$ & $90 \%$ & $95 \%$ & $85 \%$ \\
\hline
\end{tabular}

Hasil Kuesioner dari aspek Informasi Aplikasi :

1. Aplikasi RA-IBB mudah untuk digunakan.

2. Aplikasi RA-IBB berjalan sesuai dengan fungsinya.

3. Tampilan aplikasi panduan fungsi tombol mudah dipahami.

Tabel 2. Hasil Kuisioner Pengujian dari Aspek Informasi Aplikasi

\begin{tabular}{|c|c|c|c|}
\hline \multirow{2}{*}{ Responden } & \multicolumn{3}{|c|}{ Pertanyaan dan Hasil } \\
\cline { 2 - 4 } & 1 & 2 & 3 \\
\hline 1 & 5 & 4 & 4 \\
\hline 2 & 5 & 4 & 5 \\
\hline 3 & 4 & 5 & 4 \\
\hline 4 & 5 & 5 & 5 \\
\hline Jumlah & 19 & 18 & 18 \\
\hline Persentase & $95 \%$ & $90 \%$ & $90 \%$ \\
\hline
\end{tabular}

Hasil Kuisioner dari Aspek Materi :

1. Informasi rumah adat sudah sesuai dengan materi.

2. Augmented Reality rumah adat terlihat jelas.

3. Materi yang terdapat pada Aplikasi RA-IBB mudah dipahami.

4. Pertanyaan quiz sudah sesuai dengan informasi materi.

5. Rumah adat yang digunakan sudah sesuai dengan provinsi.

6. Lagu daerah yang digunakan sudah sesuai dengan asal provinsi.

7. Memudahkan siswa dalam mengenalkan rumah adat Indonesia bagian barat.

Hasil Kuisioner Pengujian dari Aspek Materi

\begin{tabular}{|c|c|c|c|c|c|c|c|}
\hline \multirow{2}{*}{ Responden } & \multicolumn{7}{|c|}{ Pertanyaan dan Hasil } \\
\cline { 2 - 8 } & 1 & 2 & 3 & 4 & 5 & 6 & 7 \\
\hline 1 & 4 & 5 & 4 & 4 & 5 & 4 & 5 \\
\hline 2 & 4 & 4 & 5 & 4 & 5 & 5 & 5 \\
\hline 3 & 5 & 4 & 4 & 5 & 5 & 5 & 5 \\
\hline 4 & 4 & 4 & 5 & 5 & 4 & 5 & 4 \\
\hline Jumlah & 17 & 17 & 18 & 18 & 19 & 19 & 19 \\
\hline Persentase & $85 \%$ & $85 \%$ & $90 \%$ & $90 \%$ & $95 \%$ & $95 \%$ & $95 \%$ \\
\hline
\end{tabular}

f. Uji coba beberapa versi Android

\begin{tabular}{|c|c|c|c|}
\hline No. & Versi OS & Spesifikasi & Keterangan \\
\hline 1. & $\begin{array}{l}\text { Android v6.0 } \\
\text { (Marshmallow) }\end{array}$ & $\begin{array}{ll}\text { a. } & \begin{array}{l}\text { Exynos } \\
\text { Quad- }\end{array} \\
& \text { core 1.4 } \\
& \text { GHz } \\
\text { b. } & 5.0 \text { inch } \\
& \text { HD } \\
& \text { TFT } \\
\text { c. } & 8 \mathrm{~GB} \\
& \text { Storage } \\
\text { d. } & 1.5 \mathrm{~GB} \\
& \text { RAM } \\
\text { e. } & \text { Camera } \\
& \text { 8MP + } \\
& \text { 5MP }\end{array}$ & $\begin{array}{l}\text { Aplikasi } \\
\text { dapat di } \\
\text { install dan } \\
\text { berjalan } \\
\text { dengan } \\
\text { baik. }\end{array}$ \\
\hline 2. & $\begin{array}{l}\text { Android v6.0.1 } \\
\text { (Marshmallow) }\end{array}$ & $\begin{array}{ll}\text { a. } & \text { Exynos } \\
& 7570 \\
& \text { Quad } \\
& (14 \mathrm{~nm}) \\
\text { b. } & 5.0 \\
& \text { inches } \\
\text { c. } & 16 / 32 \\
& \text { GB } \\
& \text { Storage } \\
\text { d. } & 2 \mathrm{~GB} \\
& \text { RAM } \\
\text { e. } & \text { Camera } \\
& 13 \mathrm{MP}+ \\
& 5 \mathrm{M} \\
\end{array}$ & $\begin{array}{l}\text { Aplikasi } \\
\text { dapat di } \\
\text { install dan } \\
\text { berjalan } \\
\text { dengan } \\
\text { baik. }\end{array}$ \\
\hline 3. & $\begin{array}{l}\text { Android v7.1.1 } \\
\text { (Nougat) }\end{array}$ & $\begin{array}{ll}\text { a. } & \begin{array}{l}\text { Octa- } \\
\text { core 2.5 }\end{array} \\
& \text { GHz } \\
& \text { Cortex } \\
& \text { A53 } \\
\text { b. } & 6.0 \\
& \text { inches } \\
\text { c. } & 64 \mathrm{~GB} \\
& \text { Storage } \\
\text { d. } & 6 \mathrm{~GB} \\
& \text { RAM } \\
\text { e. } & \text { Camera } \\
& \text { 16MP + } \\
& \text { 20MP } \\
\end{array}$ & $\begin{array}{l}\text { Aplikasi } \\
\text { dapat di } \\
\text { install dan } \\
\text { berjalan } \\
\text { dengan } \\
\text { baik. }\end{array}$ \\
\hline
\end{tabular}

\section{KESIMPULAN}

Aplikasi augmented reality berhasil dikembangkan dengan menggunakan marker based tracking dan untuk pembuatan objek 3D menggunakan aplikasi sketchup. Aplikasi ini menggunakan metode pengembangan sistem waterfall dengan 4 langkah : analisis kebutuhan, desain, implementasi \& uji coba sistem. Aplikasi ini dibuat dengan menggunakan mobile augmented reality yang berisi 18 rumah adat Indonesia dengan bentuk 3D beserta informasinya. Dalam aplikasi juga 
terdapat kuis dengan pengacakan soal menggunakan algoritma shuffle random untuk evaluasi setelah mempelajari materi dan rumah adat.

\section{REFERENSI}

Gustami, W. (2016). Rancang Bangun Multimedia Pembelajaran Interaktif Menerapkan Problem Based Learning Berbantuan Game Untuk Meningkatkan Pemahaman Siswa Smk Pada Mata Pelajaran Pemrograman Dasar.

Klimova, A., Bilyatdinova, A., \& Karsakov, A. (2018). Existing Teaching Practices in Augmented Reality. Procedia Computer Science, 136, 5-15.

Nugraha, I. G. A., Putra, I. K. G. D., \& Sukarsa, I. M. (2016). Rancang Bangun Aplikasi Augmented Reality Museum Bali Berbasis Android Studi Kasus Gedung Karangasem dan Gedung Tabanan. Lontar Komputer: Jurnal Ilmiah Teknologi Informasi, 7(2), 93-103.

Pramono, A., \& Setiawan, M. D. (2019). Pemanfaatan Augmented Reality Sebagai Media Pembelajaran Pengenalan Buah-Buahan. INTENSIF: Jurnal Ilmiah Penelitian Dan Penerapan Teknologi Sistem Informasi, 3(1), 54-68.

Rahadi, Tursina, \& Anra, H. (2017). Rancang Bangun Aplikasi Augmented Reality Berbasis Android Untuk Pengenalan Rumah Adat. Jurnal Sistem Dan Teknologi Informasi (JUSTIN), 5(4), 229-235.

Rio, U., Erlinda, S., \& Haryono, D. (2016). Implementasi Model Mobile Augmented Reality e-Booklet untuk Mempromosikan Object Wisata Unggulan Provinsi Riau dengan metode 3D Object Tracking. INOVTEK Polbeng - Seri Informatika, 1(2), 177-191.

Riskal, A. (2017). Rancang Bangun Aplikasi 3D (Tiga Dimensi) Rumah
Adat Se-Indonesia Berbasis Mobile. Scaravetti, D., \& Doroszewski, D. (2019). Augmented reality experiment in higher education, for complex system appropriation in mechanical design. Procedia CIRP, 84, 197-202.

Sutiari, N. K., Darma Putra, I. K. G., \& Sunia Raharja, I. M. (2018). Aplikasi Pengenalan Rumah Adat Indonesia Berbasis Augmented Reality. Jurnal Ilmiah Merpati (Menara Penelitian Akademika Teknologi Informasi), 6(2), 108-118.

Sylfania, D. Y. (2016). Penggunaan Augmented Reality Untuk Brosur Penjualan Laptop Berbasis Android. Jurnal Teknologi Informatika Dan Komputer Atma Luhur, 3(1), 28-36.

Wisnugroho, S., Prasetyo, A. D., \& Kurniawan, R. (2015). Aplikasi Android Pengenalan Rangka Manusia Berbasis Augmented Reality. Seminar Informatika Medis 2015, 77-86.

Yusnita, A., \& Rija'i, T. (2019). Implementasi Algoritma Shuffle Random pada Pembelajaran Panca Indra Berbasis Android. JUITA : Jurnal Informatika, 7(1), 19-24. 